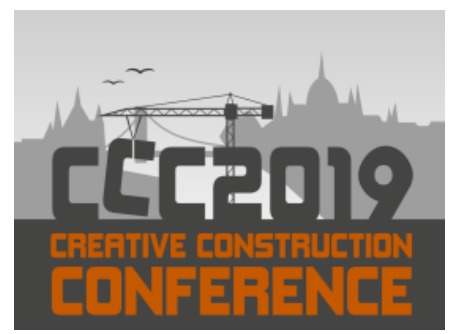

Available online at 2019.creative-construction-conference.com/proceedings/

CCC 2019

Proceedings of the Creative Construction Conference (2019) 011

Edited by: Miroslaw J. Skibniewski \& Miklos Hajdu

https://doi.org/10.3311/CCC2019-011

Creative Construction Conference 2019, CCC 2019, 29 June - 2 July 2019, Budapest, Hungary

\title{
Monitoring of concrete placement and vibration for real-time quality control
}

\author{
Sang Gyu Lee and Miroslaw J. Skibniewski \\ ${ }^{a}$ Center of Excellence in Project Management, Department of Civil and Environmental Engineering, University of Maryland, College Park, MD \\ 20742-3201,USA, e-mail: slee239@terpmail.umd.edu
}

\begin{abstract}
This paper presents a conceptual framework for monitoring concrete placement and vibration operations. The proposed design is intended to enable collection and analysis of concrete pour data using computer vision and ultrasonic positioning. The system being developed alerts a project manager when workmanship observed is not in compliance with acceptable performance standards. The paper describes key operational factors in concrete placement and vibration that need to be monitored and reviews options for realtime locating systems. Fourteen factors related to concrete placement and their corresponding parameters are determined for measurement. In regard to the real-time locating systems, Ultra-wideband, ultrasonic, and computer vision technologies satisfy the expected levels of on-site positioning range and accuracy. Along with computer vision, ultrasonic technology has been chosen over Ultra-wideband alternative due to its lower cost and comparable performance.
\end{abstract}

(C) 2019 The Authors. Published by Budapest University of Technology and Economics \& Diamond Congress Ltd..

Peer-review under responsibility of the scientific committee of the Creative Construction Conference 2019.

Keywords: concrete placement and vibration; quality control; real-time monitoring; workmanship

\section{Introduction}

Concrete placement and vibration are vital activities that turn site workmanship into an actual concrete product. Inappropriate placement and vibration adversely affect concrete quality and cause an onset and development of a concrete defect which increase direct and indirect costs of a construction project [1,2]. A defect not only requires time and cost to correct, but it also increases the time spent by an inspector to examine, evaluate, and document the defect. Furthermore, defects may lead a contractor to penalty fees or legal disputes. These events not only cause loss in the current project, but also reduce opportunities to win future projects by damaging the contractor's reputation. Thus, it is necessary for contractors to reduce defects in order to save costs and secure competitiveness in the market.

However, previous efforts to procure quality concrete have focused mainly on enhancing defect management practices before/after site operations (e.g. material preparation and site inspection). Current operational practices on concrete still remain to be observed and managed by human supervisors, which is not a practical solution for all-time monitoring of compliance; supervisory control is sometimes lax since all managers are busy dealing with the work progress. Moreover, such method involves inconsistent measurement and assessment in assuring conformity of rules due to different levels of knowledge, field experiences and cognitive abilities of the managers. The dynamic environment of the construction site as well as a number of ongoing tasks and labourers make it even more difficult to achieve

*Corresponding author: Miroslaw J. Skibniewski, email: mirek@umd.edu 
Sang Gyu Lee/ Proceedings of the Creative Construction Conference (2019) 011

https://doi.org/10.3311/CCC2019-011

continuous and immaculate detection of poor workmanship. For these reasons, immediate and corrective actions are hardly made during the concrete operations. Instead, concrete defects are rather inspected and corrected after the concrete is already hardened.

Therefore, in order to help the managers to assure the quality of concrete operations and to proactively prevent the concrete defects, we propose a system designed to monitor the quality of workmanship in regard to concrete placement and vibration. The system will automatically collect data for concrete placement and vibration practices that may cause a quality issue. It will send an alert to a user (e.g. a manager and a superintendent) immediately when the concrete work-related parameters are out of the required range set by the user. This paper introduces the first part of our study in which we will 1) determine key operational factors (KOF) of concrete placement and vibration that play key roles in achieving concrete quality, and 2) investigate the appropriate real-time locating systems.

\section{Current concrete work and defect inspection procedures}

The general workflow of concrete activities and defect inspection is shown in Fig. 1. It involves the procedures that concrete is prepared, operated, and inspected in a project. During the entire course of concrete work and defect inspection, many tools have been developed and employed at multiple checkpoints as a safeguard so that any nonconformance is discovered, and a remedial action is taken.

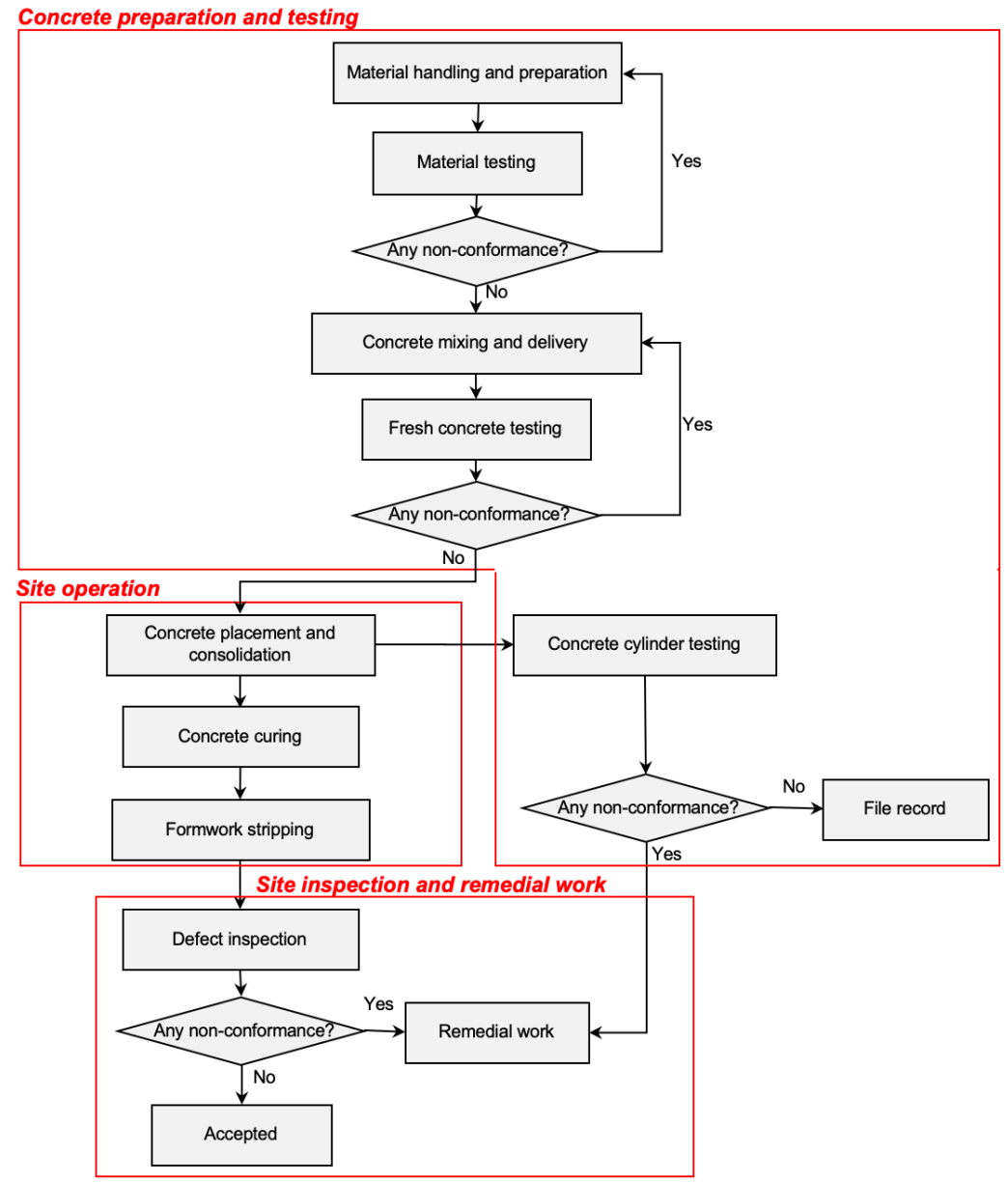

Fig. 1. Procedures for concrete placement and defect inspection.

The first stage is concrete preparation and testing. Materials for mixing concrete are prepared in this stage according to standard specifications. The individual materials used for a mix as well as the freshly mixed concrete are tested for 
Sang Gyu Lee/ Proceedings of the Creative Construction Conference (2019) 011

https://doi.org/10.3311/CCC2019-011

quality assurance. At this pre-operational stage, it is common that provisions in a construction contract require a contractor and a supplier to comply with American Society for Testing and Materials (ASTM) standard specifications and testing methods [3,4]. They introduce the procedures for measuring and preparing materials, sampling and testing methods of individual materials, and field testing of freshly mixed concrete.

When concrete is delivered to a site, a general contractor and subcontractors carry out on-site operations. During the operation, a site manager walks around to supervise whether the work practices are appropriate or not. There are manuals and guides which help to understand the standards and recommended operational practices. They serve as a reference by providing detailed information and instructions about concrete operations. For example, ACI 309R-96 Guide for consolidation of concrete introduces mechanism and methods of consolidation and recommended practices [5]. ACI 304R-00 Guide for measuring, mixing, transporting, and placing covers the recommended field practices on placing concrete in chapter 5 and the practices on concrete finishing in chapter 6 [6].

After stripping formwork, concrete is inspected to check whether the outcome quality satisfies all aesthetic and structural requirements. If an inspector finds a construction error or a defect, it will be reported to a project manager, and workers will be ordered to carry out remedial work. Many documents share information about concrete defect inspection based on which a project manager diagnoses the significance of a defect, plans a repair, and seeks for a way to prevent it $[7,8]$. Besides, tools for automated inspection have been studied and developed to capture quality deviation quickly and accurately. Zhu et al. [9] introduced a method that utilizes image processing techniques for automated detection and measurement of surface air pockets on concrete. In the study of Radopoulou et al. [10], a framework that automates the process of acquiring data of defects on a road such as cracks, patches, and potholes was proposed. In addition to the inspection tools, there have been efforts in developing and improving defect management information systems to encourage utilization of detect data by streamlining data input, storage, and retrieval. These studies improved quality and security of defect data and enabled quick documentation. Kim et al. [11] provided a webbased defect inspection and management system with an apartment housing construction project. The defect data were acquired by using a Personal Digital Assistant (PDA) to fill a checklist at a site.

The review of the previous efforts indicates that there are not many hands-on tools and systems developed for controlling concrete operations and preventing concrete detects. Although proper concrete placement and vibration are essential to satisfy the quality requirements of a structure and to decrease the risk of reduced lifespan, just guides and manuals have been advised to be referenced. Faulty site workmanship and concrete defects are still common, resulting in numerous legal disputes. As long as the supervising concrete work remains to be conducted by human supervisors, observing noncompliance of the rules and the guides during work will be prone to errors and costly [2,12]. The fact that all-time monitoring of site operations is not feasible with the current supervision method has led project managers to rely on a diagnostic and corrective approach, which is to inspect the quality of final components and repair a defect if observed. The truth is, an inspection is merely a method for detecting non-conformances 'after-the-fact', meaning that the management of defects by means of inspections is inherently reactive [2]. While corrective actions are very important to meet the desired final quality level, they are more costly than taking preventatives, and work results are often not as good as the originally planned quality $[5,13]$.

\section{Methodology}

We propose a conceptual framework to monitor the quality of workmanship in real-time and to alert a manager/superintendent when concrete work-related parameters are unacceptable. To develop the framework, this section determines key operational factors and investigates real-time locating systems. This study focuses on concrete placement with a concrete pump car (also known as a truck-mounted mobile pump) and consolidation with an internal concrete vibrator (also as known as a spud or poker vibrator), both of which are commonly used at construction sites. 
Sang Gyu Lee/ Proceedings of the Creative Construction Conference (2019) 011

https://doi.org/10.3311/CCC2019-011

\subsection{Determining key operational factors (KOFs)}

Various documents such as books, websites, articles, reports, journal papers, and guides about workmanship and concrete defects were reviewed to determine the key operational factors (KOFs) which represent the critical workmanship to concrete quality. Then, their parameters were investigated to clarify the objects and motions of interest regarding each KOF. Such parameter gives a better insight into how to measure the KOF and how to determine its violation. Table 1 summarizes the fourteen workmanship factors and their parameters.

Table 1. Key operational factors and their parameters

\begin{tabular}{|c|c|c|}
\hline \multicolumn{2}{|r|}{ Key operational factor (KOF) } & Parameter \\
\hline 1 & $\begin{array}{l}\text { Crews should deposit only as much concrete as can be } \\
\text { consolidated efficiently }\end{array}$ & $\begin{array}{l}\text { Depth of freshly placed concrete layer } \\
\text { Duration that a pump hose stays at one place }\end{array}$ \\
\hline & Placement should continue before a cold joint develops. & Time gap of placement between layers \\
\hline 2 & Compaction must be done while concrete is still plastic & Time gap between placement and vibration \\
\hline 3 & Placing concrete should be from an appropriate height & Height of the discharging point at pump hoses \\
\hline 4 & Concrete should drop vertically & $\begin{array}{l}\text { Angle of the discharging point at pump hoses } \\
\text { Angle between the discharging point at pump hoses and deposited } \\
\text { location of concrete }\end{array}$ \\
\hline 5 & Concrete should not be placed directly on reinforcing bars & Area that dropping concrete touches rebar \\
\hline 6 & Concrete should be vibrated for an appropriate duration & Duration that a vibrator tip stays as inserted into concrete \\
\hline 7 & Vibration sticks should be inserted to the sufficient depth & Depth of a vibrator's insertion into concrete \\
\hline 8 & $\begin{array}{l}\text { Distance between insertions of the vibrator head should be } \\
\text { appropriate }\end{array}$ & Distance between insertions \\
\hline 9 & $\begin{array}{l}\text { Vibrators should be kept close of the form face to avoid defects } \\
\text { from insufficient vibration }\end{array}$ & $\begin{array}{l}\text { Distance between forms (where concrete is placed) and their closest } \\
\text { insertion }\end{array}$ \\
\hline 10 & Vibrators should not be allowed to touch the forms & Duration that a vibrator is touching a form \\
\hline 11 & Vibrators should not be held against the reinforcement & Duration that a vibrator is touching a reinforcing bar \\
\hline 12 & $\begin{array}{l}\text { Vibrators should quickly penetrate the concrete layer and be } \\
\text { removed slowly to remove entrapped air }\end{array}$ & Vibrator's insertion/withdrawal speeds \\
\hline 13 & Vibrators should be inserted and withdrawn vertically & Angle of the vibrator when inserted/withdrawn \\
\hline 14 & Dragging vibrator through the concrete should be prohibited & Distance of a vibrator's horizontal movement while inserted \\
\hline
\end{tabular}

\subsection{Review of real-time locating systems (RTLS)}

Real-time locating system (RTLS) is a system which continuously determines a position of an object in real-time. In order to choose the best approach for the addressed problem, possible options for RTLS and their fundamental capabilities were reviewed and compared. Table 2 was excerpted and updated from the studies of Karunaratne et al. [14] and Gong et al. [15].

Table 2. Comparison of real-time locating systems (RTLS).

\begin{tabular}{|c|c|c|c|}
\hline RTLS & Description & Reading range & Accuracy \\
\hline GPS & $\begin{array}{l}\text { A space-based satellite navigation system that allows a GPS receiver to } \\
\text { calculate its position by precisely timing the signals sent by GPS satellites } \\
\text { high above the Earth. }\end{array}$ & $\begin{array}{l}\text { Used where satellite signals } \\
\text { reach [16] }\end{array}$ & $\begin{array}{l}0.01 \quad \mathrm{~m} \text { with } \\
\text { differential GPS } \\
2-5 \text { m others }\end{array}$ \\
\hline RFID & $\begin{array}{l}\text { A technology that uses radio waves as a way of identifying, locating, and } \\
\text { tracking objects. }\end{array}$ & $\begin{array}{l}\text { Passive } 10 \mathrm{~m} \\
\text { Active } 100 \mathrm{~m}\end{array}$ & $1-3 \mathrm{~m}$ \\
\hline Infrared (IR) & A technology that uses diffused IR to achieve room-level locating. & $10 \mathrm{~m}$ & $5-10 \mathrm{~m}$ \\
\hline $\begin{array}{l}\text { Wi-Fi (IEEE } \\
802.11)\end{array}$ & A technology that relies on 802.11 networking for real-time locating. & $100 \mathrm{~m}$ & $1-5 \mathrm{~m}$ \\
\hline $\begin{array}{l}\text { Zigbee (IEEE } \\
802.15 .4)\end{array}$ & $\begin{array}{l}\text { A technology that operates based on the IEEE } 802.15 .4 \text { standard for } \\
\text { localization. }\end{array}$ & $10-100 \mathrm{~m}$ & $1 \mathrm{~m}$ \\
\hline $\begin{array}{l}\text { Ultra-wideband } \\
\text { (UWB) }\end{array}$ & A technology that uses radio waves with large band widths to track radio tags. & $30 \mathrm{~m}$ & $0.01 \mathrm{~m}$ \\
\hline Cellular RTLS & $\begin{array}{l}\text { The cellular-based RTLS relies on resolving the position of the mobile device } \\
\text { by indicating the cell with which the mobile device is registered. }\end{array}$ & $\begin{array}{l}\text { Can be used where cellular } \\
\text { networks are available }\end{array}$ & $50-200 \mathrm{~m}$ \\
\hline Computer Vision & $\begin{array}{l}\text { A technology for detecting objects in an image and recognizing the object in } \\
\text { successive video frames. }\end{array}$ & Visible distance & A few centimetres \\
\hline Ultrasonic & A technology that uses ultrasonic pulses to calculate receiver's position. & $* 30 \mathrm{~m}$ & $0.02 \mathrm{~m}[17]$ \\
\hline
\end{tabular}


Sang Gyu Lee/ Proceedings of the Creative Construction Conference (2019) 011

https://doi.org/10.3311/CCC2019-011

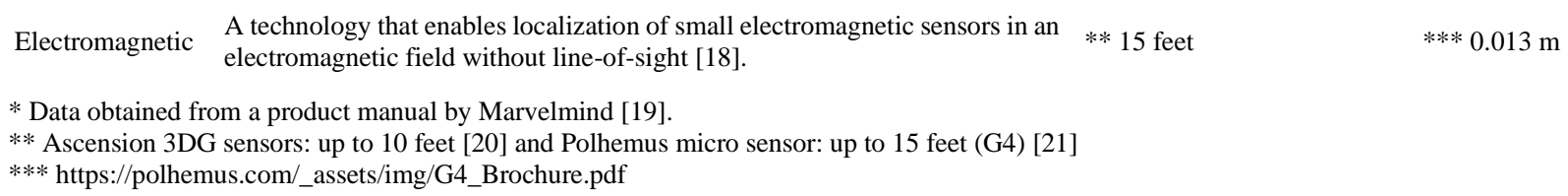

In order to measure the parameters of KOFs accurately and instantly, we determined that the minimum reading range as 10 metres, and an error is expected to be lower than 10 centimetres to avoid misinterpretations or wrong decisions. Ultra-wideband (UWB), ultrasonic (US) and computer vision are considered to meet our needs in terms of the reading range and the accuracy. While UWB and US have similar mechanisms of calculating positions, performance and output datatype, US systems are less expensive than UWB systems. Therefore, along with computer vision, US was chosen over UWB due to its cost-effectiveness.

\subsection{Ultrasound positioning system}

Ultrasonic positioning system utilizes ultrasonic waves that have higher frequencies than the audible limit of human hearing to get a tag's location [14]. The tag attached to an object emits a unique ultrasonic signal, and the signal is sensed by receivers. The tag's location can be figured out using the information of the signal such as speed, departure time and arrival time. Ultrasonic positioning system has many advantages which made it gain popularity. Ultrasound waves cannot penetrate walls and are negligibly affected by the surroundings, they which means that the system is not disturbed by ultrasonic waves in other rooms [16]. It provides with centimetre-level accuracy with a low system cost, and it can track multiple mobile nodes simultaneously [22]. However, though it is scalable, room-level applications are typical because the cost increases as a larger area is covered. In addition, its performance can be influenced largely by the environmental conditions such as humidity and temperature [23]. Ultrasonic signals quickly fade away and travel a short distance when humidity is high, and the speed of the signal is directly affected by temperature. Many devices attempt to offset these effects by integrating it with a temperature or a humidity sensor. External noises could be another problem to its accuracy, but they are often low-frequency and can be filtered by algorithms [22].

Ultrasound waves have been widely used in the construction field. Zhou et al. [24] developed an Internet-of-Thingsbased system to achieve improved safety for underground construction sites. They installed ultrasonic detectors which have the centimetre-level accuracy to construction vehicles such as excavators and dump trucks to improve safety. Lee et al. [25] developed a mobile safety monitoring system which senses human and inanimate objects by utilizing ultrasonic and infrared sensors. The previous applications were mostly to measure distances between two points, not to get three-dimensional coordinates in a space.

\subsection{Computer vision}

Computer-vision is the theory and technology for understanding how computers can be made to gain high-level understanding from digital images or videos [26]. Today, as more images and videos are obtained and shared, a vast amount of information can be extracted and used by computer vision. Computer vision RTLS is useful especially when it is not practical to attach a tag to an object. While other systems such as RFID can gather locational information for objects, computer vision technology enables to extract additional information such as size, colour, and texture of an object. Since it saves visual data in pixels, long range recognition is viable as long as the resolution is high and the sight is clean. However, the instrument cost for entire RTLS can be expensive when it involves high-resolution cameras and computers equipped with powerful central and graphics processing units. Its accuracy can vary depending on the image resolution and visibility. Besides, the sizes of images or videos are usually large, so transferring them to a computer may require a high speed of network.

There are two different approaches in terms of object detection in computer vision: 1) traditional machine-learningbased and 2) deep-learning-based. The traditional approach employs hand-coding to extract certain features of an 
object using feature descriptors. Feature extraction is to reduce the image information to a feature vector which represents unique and identifiable parts of the image [27]. For example, Sobel detectors are used for edge detection while Laplacian of Gaussian (LoG) is used for blob detection (Fig. 2). After that, a machine learning tool is used to determine whether the observed object is classified as the trained object. On the other hand, the deep-learning approaches such as R-CNN and YOLO use neural networks to extract and learn useful representations of features directly from the data [28]. In these approaches, the model learns by itself to select the best-performing filters to detect objects. They have become more powerful and shown successful applications in many fields such as a self-driving car.
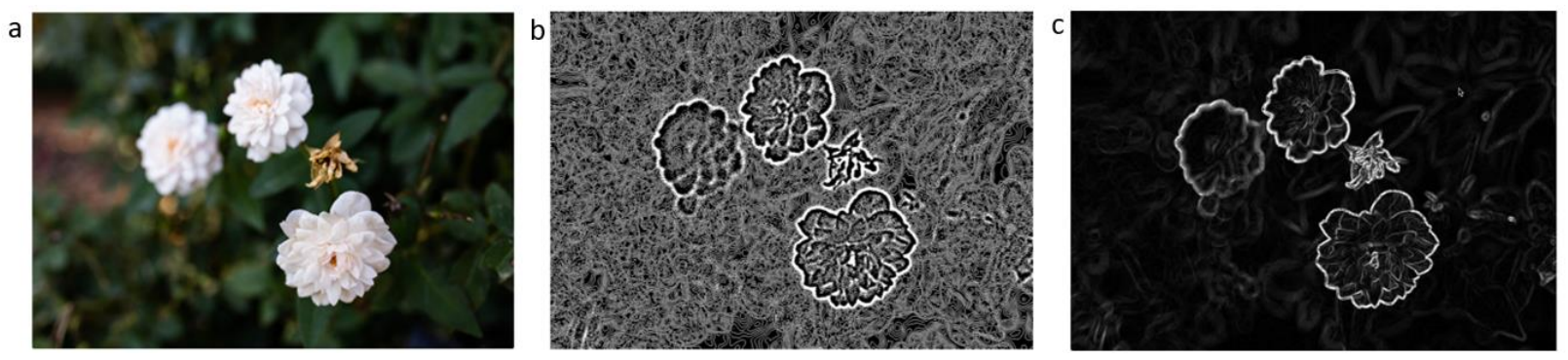

Fig. 2. Examples of feature descriptors. (a) original; (b) Laplacian of Gaussian (LoG); (c) Sobel.

The next application is object tracking, which is to find an object in a current frame assuming that the object has been tracked successfully in the previous frames. It is different from a mere repetition of detection because some information such as location, direction, and speed of motion captured from the previous frames can be used for tracking objects in successive frames. Unlike object detection, object tracking does not necessarily identify the objects to be tracked because it leverages the relationship between successive image frames. This can allow object tracking algorithms more computationally cheaper and efficient than running object detection repetitively. One of the popular object tracking algorithms is the Meanshift tracker (Fig. 3 (a)). It uses histograms of an object in the current image to figure out its location in the next image frame by minimizing the distance between two probability density functions [29]. Background subtraction algorithms are also useful to extract an image's foreground when using stationary cameras (Fig. 3. (b)).

In addition to object detection and tracking, computer vision includes the domain of 3D analysis from 2D images, which is called as stereo vision. Given two or more images of the same scene, its 3D shape can be represented. Implementation of stereo vision is necessary to get 3D location data of the object detected or tracked in an image. In multi-view stereo vision, two or more cameras are displaced at known locations and orientations, and they look at a same scene. Then, a disparity of features between the stereo images are used to calculate the distance. Fig. 3. (c) shows an example of binocular stereo vision. The depth information is extracted by comparing left-view and right-view images.
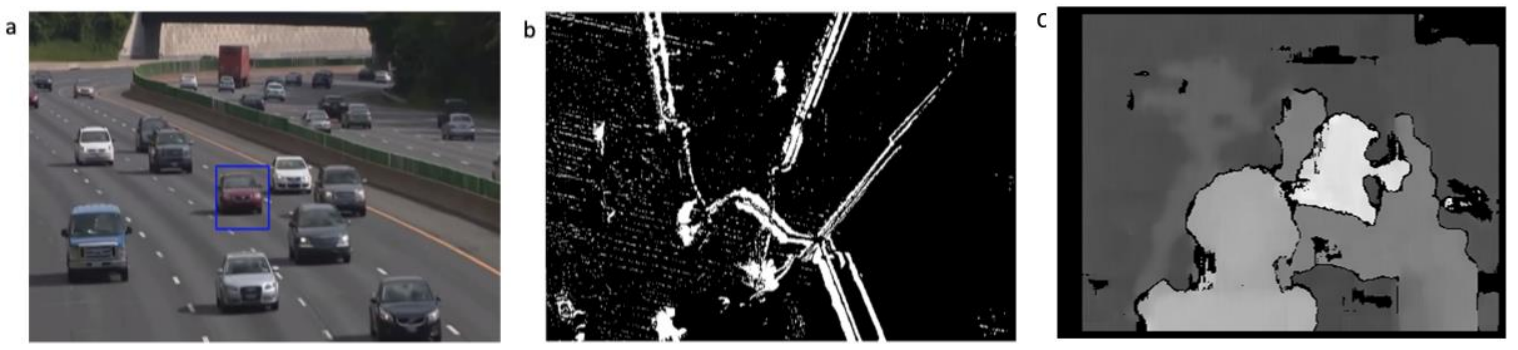

Fig. 3. (a) Meanshift tracker applied to car tracking [30]; (b) background subtraction applied to a video clip [31]; (c) example of stereo vision (depth map) [32].

Many of the reviewed studies of concrete inspection systems are the examples of object detection using computer vision. Not only concrete, but also other materials such as timber and steel were recognized and inspected [33, 34]. Background subtraction algorithms have been employed for reliable detection and tracking of objects. Chi et al. [35] 
Sang Gyu Lee/ Proceedings of the Creative Construction Conference (2019) 011

https://doi.org/10.3311/CCC2019-011

introduced a method for detection and recognition of heavy equipment and workers, which employed classifiers and background subtraction algorithms to recognize objects from videos. Yang et al. [36] developed a vision-based system for assessing crane activities. They used a background subtraction algorithm to segment the crane from other elements. Stereo vision has mostly been used for automation of updating and monitoring progress of a project. Bugler et al. [37] presented a method for estimating an activity status and progress of an excavation work. By using feature-based stereo, they created a 3D point cloud of a site space from images taken from an unmanned aerial vehicle (UAV) and estimated the excavated volume.

\subsection{Conceptual framework of the system}

The conceptual framework and flow of implementing the system is presented in Fig. 4. The system performs data collection on concrete placement and vibration activities from three different sources: 3D model, ultrasonic positioning sensors and tags, and a pair of cameras. A 3D model contains information such as locations of forms and reinforcing bars, a space name, compartment, and a concrete element type. Ultrasonic devices and computer vision are responsible for collecting information of moving objects. Both can track locations of objects, but computer vision can be also used to estimate an activity status in addition to the locations. For example, it can detect the status of placement activity by checking whether concrete is dropping from the hose or not. Workmanship is monitored based on the information collected from the three sources, and the system immediately alerts the site manager when this information indicates that the workmanship is faulty and unacceptable.

The first step of system implementation includes acquisition of a 3D model, installation of a pair of cameras and ultrasonic sensors, and camera calibration. Cameras and ultrasonic positioning system should be installed where the scene can be recorded with minimum occlusion because they may lose accuracy of detecting or tracking an object when it is partially or entirely occluded. After completing calibration of cameras, conversion matrices need to be calculated from each system to integrate different coordinate systems. This can be done by comparing a set of points collected from different sources and calculating coordinate conversion matrices. When all devices are set up and conversion matrices are known, object locations during concrete placement and vibration are collected. The data are continuously compared to the thresholds of KOFs set by a manager to make sure they are within an acceptable range. If a violation is detected, the system extracts and compiles the violation data and sends a warning message to the manager. The data are trimmed and organized so that the manager can understand the issue quickly and accurately. Visualized location data with graphs and statistical summary is attached to a warning message in order to facilitate comprehension and communication of stakeholders. 


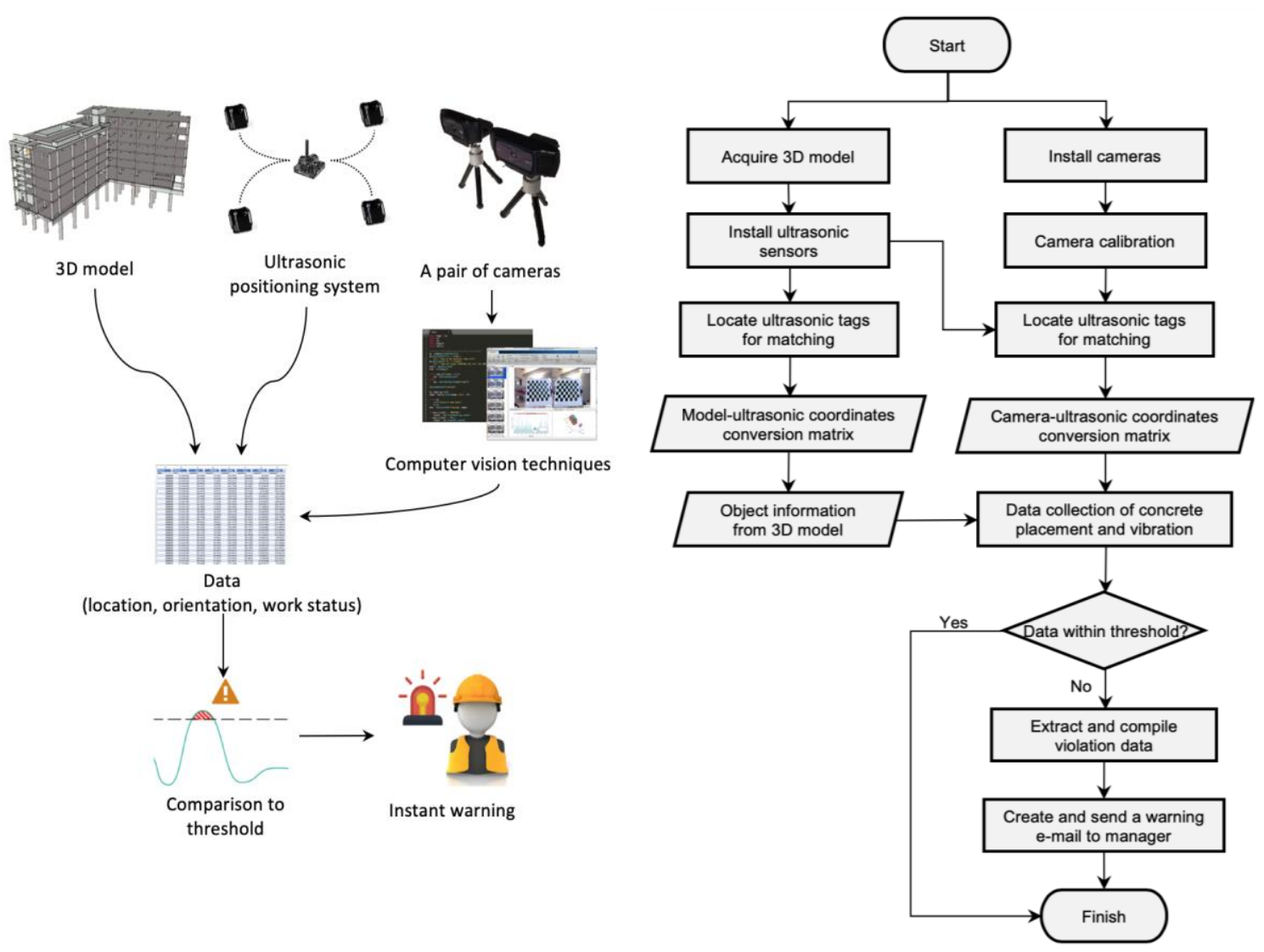

Fig. 4. (a) conceptual framework of the proposed system; (b) flow of implementation

\section{CONCLUSION}

The needs for real-time monitoring of concrete workmanship have arisen to overcome the inefficiency and inaccuracy of the current supervising method. To provide managers with timely and appropriate data as a proactive and preventive approach, this paper introduced the conceptual framework and implementation flow of an automated system for monitoring concrete placement and vibration work. Fourteen KOFs and their parameters were determined by examining document about workmanship and concrete defects. Then, RTLS were reviewed and selected by comparing their reading range and accuracy. We determined to utilize ultrasonic and computer vision with the information extracted from a 3D model. Lastly, the conceptual framework and implementation flow of the proposed system are introduced. The remaining steps include the full-scale development and testing of the system. A mock-up experiment at a testbed is planned at the University of Maryland to perform data acquisition and test reliability of the system. Ultrasonic positioning system will be tested to check if any condition decreases data accuracy or acquisition rate. In regard to computer vision, algorithms for object detection and tracking will be tested. Besides, the accuracy of stereo vision will be evaluated by comparing the actual measurement and the estimated position from the cameras. Technical and practical difficulties will be addressed after the test, and their potential solutions will be explored.

\section{References}

[1] P. E. Love, "Auditing the indirect consequences of rework in construction: a case based approach," Managerial Auditing Journal, vol. 17, no. 3, pp. 138-146, 2002. https://doi.org/10.1108/02686900210419921.

[2] R. Lundkvist, J. H. Meiling, and M. Sandberg, "A proactive plan-do-check-act approach to defect management based on a Swedish construction project," Construction Management and Economics, vol. 32, no. 11, pp. 1051-1065, 2014. https://doi.org/10.1080/01446193.2014.966733.

[3] ASTM International. ASTM Construction Standards: Supporting the Building Industry. Available: https://www.astm.org/ABOUT/images/construction.pdf. Accessed on 19 Feb 2018. 
[4] K. A. Hooker. How ASTM standards affect the contractor. Available: http://www.concreteconstruction.net/business/management/how-astmstandards-affect-the-contractor_o. Accessed on 1 Mar 2018.

[5] ACI Committee 309, 309R-96 Guide for Consolidation of Concrete, 2014. [Online]. Available: https://www.concrete.org/store/productdetail.aspx?ItemID=30905\&Language=English\&Units=US_Units. ISBN: 9780870319105

[6] ACI Committee 304, 304R-00: Guide for Measuring, Mixing, Transporting, and Placing Concrete, 1989. [Online]. Available: https://www.concrete.org/store/productdetail.aspx?ItemID=30400\&Format=DOWNLOAD\&Language=English\&Units=US_Units. ISBN: 9780870313080

[7] Portland Cement Association (PCA), Concrete Slab Surface Defects: Causes, Prevention, Repair, 2011. [Online]. Available: https://www.oboa.on.ca/events/2009/sessions/files/Slab\%20Surface\%20Prevention\%20Repair.pdf. Accessed on 2018.02.20. ISBN: 0-89312$212-Z$

[8] Graniterock. Concrete Surface Defects. Available: http://www.graniterock.com/technical_reports/concrete-surface-defects1539? category_id=89. Accessed on 20 Feb 2018.

[9] Z. Zhu and I. Brilakis, "Detecting air pockets for architectural concrete quality assessment using visual sensing," Journal of Information Technology in Construction (ITcon), vol. 13, no. 7, pp. 86-102, 2008.

[10] S. C. Radopoulou, I. Brilakis, K. Doycheva, and C. Koch, "A Framework for Automated Pavement Condition Monitoring," Construction Research Congress, pp. 770-779, 2016. https://doi.org/10.1061/9780784479827.078.

[11] Y. S. Kim, S. W. Oh, Y. K. Cho, and J. W. Seo, "A PDA and wireless web-integrated system for quality inspection and defect management of apartment housing projects," Automation in Construction, vol. 17, no. 2, pp. 163-179, 2008. https://doi.org/10.1016/j.autcon.2007.03.006.

[12] C.-S. Park, D.-Y. Lee, O.-S. Kwon, and X. Wang, "A framework for proactive construction defect management using BIM, augmented reality and ontology-based data collection template," Automation in Construction, vol. 33, pp. 61-71, 2013. https://doi.org/10.1016/j.autcon.2012.09.010.

[13] L. K. Kennedy, The Contractor's Guide to Quality Concrete Construction. 2005. ISBN: 9780870311673

[14] L. A. Karunaratne, "Real-time locating systems in agriculture: technical possibilities and limitations," Department of Information Technology, Institutionen för informationsteknologi, 2010.

[15] J. Gong, Y. Yu, R. Krishnamoorthy, and A. Roda, "Real-time tracking of concrete vibration effort for intelligent concrete consolidation," Automation in Construction, vol. 54, pp. 12-24, 2015. https://doi.org/10.1016/j.autcon.2015.03.017.

[16] J. Qi and G.-P. Liu, "A Robust High-Accuracy Ultrasound Indoor Positioning System Based on a Wireless Sensor Network," Sensors, vol. 17, no. 11, p. 2554, 2017. https://doi.org/10.3390/s17112554.

[17] J. Li, G. Han, C. Zhu, and G. Sun, "An indoor ultrasonic positioning system based on toa for internet of things," Mobile Information Systems, vol. 2016, 2016. http://dx.doi.org/10.1155/2016/4502867.

[18] A. M. Franz, T. Haidegger, W. Birkfellner, K. Cleary, T. M. Peters, and L. J. I. t. o. m. i. Maier-Hein, "Electromagnetic tracking in medicinea review of technology, validation, and applications," IEEE Transactions on Medical Imaging, vol. 33, no. 8, pp. 1702-1725, 2014. 10.1109/TMI.2014.2321777.

[19] Marvelmind Robotics, Marvelmind indoor navigation system operating manual. [Online]. Available: https://marvelmind.com/pics/marvelmind_navigation_system_manual.pdf.

[20] Ascension Technology Corporation. 3D guidance 3 sensors. Available: https://estkl.com/images/PDF/Ascension/8300316_rev001_3DG_sensors_email.pdf. Accessed on 27 Feb 2019.

[21] V. J. V. R. Kindratenko, "Calibration of electromagnetic tracking devices," Virtual Reality, vol. 4, no. 2, pp. 139-150, 1999. https://doi.org/10.1007/BF01408592.

[22] F. Ijaz, H. K. Yang, A. W. Ahmad, and C. Lee, "Indoor positioning: A review of indoor ultrasonic positioning systems," in 2013 15th International Conference on Advanced Communication Technology (ICACT), 2013, pp. 1146-1150: IEEE.

[23] D. A. Bohn, "Environmental effects on the speed of sound," in Audio Engineering Society Convention 83, 1987, vol. 36, no. 4: Audio Engineering Society.

[24] C. Zhou and L. Ding, "Safety barrier warning system for underground construction sites using Internet-of-Things technologies," Automation in Construction, vol. 83, pp. 372-389, 2017. https://doi.org/10.1016/j.autcon.2017.07.005.

[25] U.-K. Lee, J.-H. Kim, H. Cho, and K.-I. Kang, "Development of a mobile safety monitoring system for construction sites," Automation in Construction, vol. 18, no. 3, pp. 258-264, 2009. https://doi.org/10.1016/j.autcon.2008.08.002.

[26] "Computer vision," Wikipedia. Available: https://en.wikipedia.org/wiki/Computer_vision

[27] The MathWorks. Feature extraction for compact representation of image data in computer vision. Available: https://www.mathworks.com/discovery/feature-extraction.html. Accessed on 1 Mar 2018.

[28] The MathWorks. Deep Learning for Image Processing. Available: https://www.mathworks.com/help/images/deep-learning.html. Accessed on Feb 202018.

[29] T. Vojir, J. Noskova, and J. Matas, "Robust scale-adaptive mean-shift for tracking," Pattern Recognition Letters, vol. 49, pp. 250-258, 2014. https://doi.org/10.1016/j.patrec.2014.03.025.

[30] E. Chung, Traffic Tracking Car using OpenCV - Meanshift algo. Available: https://www.youtube.com/watch?v=NyR_7e7JXAA. Accessed on 2019, 21 Jan.

[31] Hospital Construction, Medley of concrete-pumping Available: https://www.youtube.com/watch?v=b9iDvyTVZ3k\&index=4\&list=PL1sEfXWY1xnDYz4gL1Kzg6HG6Ek5Wl_WO\&t=223s. Accessed on 2019, 17 Jan.

[32] University of Tsukuba Stereo Dataset [Online]. Available: http://www.cvlab.cs.tsukuba.ac.jp/dataset/tsukubastereo.php

[33] M. Riggio, J. Sandak, and S. Franke, "Application of imaging techniques for detection of defects, damage and decay in timber structures onsite," Construction and Building Materials, vol. 101, pp. 1241-1252, 2015. https://doi.org/10.1016/j.conbuildmat.2015.06.065.

[34] K.-W. Liao and Y.-T. Lee, "Detection of rust defects on steel bridge coatings via digital image recognition," Automation in Construction, vol. 71, pp. 294-306, 2016. https://doi.org/10.1016/j.autcon.2016.08.008. 
Sang Gyu Lee/ Proceedings of the Creative Construction Conference (2019) 011

https://doi.org/10.3311/CCC2019-011

[35] S. Chi and C. H. Caldas, "Automated object identification using optical video cameras on construction sites," Computer-Aided Civil Infrastructure Engineering, vol. 26, no. 5, pp. 368-380, 2011. https://doi.org/10.1111/j.1467-8667.2010.00690.x.

[36] J. Yang, P. Vela, J. Teizer, and Z. Shi, "Vision-based tower crane tracking for understanding construction activity," ASCE Journal of Computing in Civil Engineering, vol. 28, no. 1, pp. 103-112, 2012. https://doi.org/10.1061/(ASCE)CP.1943-5487.0000242.

[37] M. Bügler, G. Ogunmakin, J. Teizer, P. A. Vela, and A. Borrmann, "A comprehensive methodology for vision-based progress and activity estimation of excavation processes for productivity assessment," in Proceedings of the EG-ICE Workshop on Intelligent Computing in Engineering, 2014, pp. 1-10. 